\title{
Hox genes reveal variations in the genomic DNA of allotetraploid hybrids derived from Carassius auratus red var. (female) $x$ Cyprinus carpio L. (male)
}

\author{
Rurong Zhao ${ }^{1,2+}$, Yude Wang ${ }^{1,2+}$, Li Zou ${ }^{3+}$, Yaxin Luo ${ }^{1,2}$, Huifang Tan ${ }^{1,2}$, Jiajun Yao ${ }^{1,2}$, Minghe Zhang ${ }^{1,2}$ and
} Shaojun $\mathrm{Liu}^{1,2^{*}}$ (D)

\begin{abstract}
Background: Hox transcription factors are master regulators of animal development. Although highly conserved, they can contribute to the formation of novel biological characteristics when modified, such as during the generation of hybrid species, thus potentially serving as species-specific molecular markers. Here, we systematically studied the evolution of genomic sequences of Hox loci in an artificial allotetraploid lineage (4nAT, $4 n=200)$ derived from a red crucian carp ( $+, R C C, 2 n=100) \times$ common carp $(\hat{0}, C C, 2 n=100)$ cross and its parents (RCC and CC).

Results: PCR amplification yielded 23 distinct Hox gene fragments from 160 clones in 4nAT, 22 fragments from 90 clones in RCC, and 19 fragments from 90 clones in CC. Sequence alignment of the HoxA3a and HoxC10a genes indicated both the inheritance and loss of paternal genomic DNA in 4nAT. The HoxA5a gene from 4nAT consisted of two subtypes from RCC and two subtypes from CC, indicating that homologous recombination occurred in the 4nAT hybrid genome. Moreover, 4nAT carried genomic pseudogenization in the HoxA10b and HoxC13a loci. Interestingly, a new type of HoxC9a gene was found in 4nAT as a hybrid sequence of CC and RCC by recombination in the intronic region.
\end{abstract}

Conclusion: The results revealed the influence of Hox genes during polyploidization in hybrid fish. The data provided insight into the evolution of vertebrate genomes and might be benefit for artificial breeding programs.

Keywords: PCR survey, Hox gene, Allotetraploid hybrid, Evolution

\section{Background}

Genome duplication, and therefore polyploidy, can occur during animal evolution [1, 2]. Two types of polyploidy have been identified based on genetic origin: autopolyploidy, which originates from the genome duplication of a single species, and allopolyploidy, which occurs via interspecific hybridization and results in haploid chromosomes inherited from different species. Allopolyploidy is prevalent in nature, suggesting the evolutionary advantage of

\footnotetext{
* Correspondence: Isj@hunnu.edu.cn

${ }^{\dagger}$ Rurong Zhao, Yude Wang and Li Zou contributed equally to this work. 'State Key Laboratory of Developmental Biology of Freshwater Fish, Hunan Normal University, Changsha 410081, Hunan, People's Republic of China ${ }^{2}$ College of Life Sciences, Hunan Normal University, Changsha 410081, Hunan, People's Republic of China

Full list of author information is available at the end of the article
}

maintaining genetic heterogeneity [3]. Allopolyploid plays an important role in facilitating the activation of cryptic mobile elements and rapid genomic change [4]. This 'genomic shock' has been reported in many allopolyploid plants and occurs through gene loss, chromosome mispairing, retrotransposon activation, altered methylation, or rearrangements between parental genomes. These can lead to novel gene sequences or differential homologous gene expression in hybrids [5]. After a short period of laboratory experiments, chromosmal rearragements, duplications and deletions of chromosome segments, and shifts in ploidy have been observed and these appear to be adaptive [6]. Changes in genome structure usually have a direct impact on the phenotype and can contribute to individual adaptation [7]. Rapid genomic DNA changes have been 
described in several allopolyploid plants [8]. Compared to plants, animals rarely undergo allopolyploidy. Therefore, the genome variations during the animal allopolyploidy process are unclear [9].

In a previous study, we obtained fertile allotetraploid hybrids from the interspecific hybridization of red crucian carp (RCC; Carassius auratus red var.,,$+ 2 \mathrm{n}=100$ ) with common carp (CC; Cyprinus carpio L., $\hat{0}, 2 \mathrm{n}=100)[10]$. Although the $F_{1}$ and $F_{2}$ progenies were diploid hybrids $(2 n=100)$, fertile allotetraploid offspring of both sexes were produced from the $F_{3}$ and later generations (Fig. 1) [11]. These allotetraploid offspring were used to generate rapidly growing and strongly resistant infertile triploids by hybridization with diploid fishes [12]. Hybrid polyploid fish have wide applications in the Chinese fish industry and they also provide an opportunity to study the molecular and genetic mechanisms that underlie the origination of evolutionary novelties including genome evolution and adaptation. Previous studies confirmed the rapid genomic DNA changes in 4nAT [13], and in this study we investigated the genetic elements susceptible to rapid genomic changes.

Hox genes belong to a large family of transcription factors. They are organized in clusters within the genome and are characterized by a homeobox, which encodes a DNA-binding motif known as the homeodomain [14, 15]. $H o x$ genes and Hox clusters provide evidence that rounds of genome duplications (the one-to-four (-to-eight-to-more in fish) rule) occur in vertebrates [16]. Recent studies have demonstrated that Hox gene clusters are fragmented, reduced, or expanded in many animals. These findings correlate with morphological changes occurring during evolution [17]. The HoxC9 is a regulator of body patterning and development. Its expression has been described in the hind limb blood vessels of mice [18] and the axial vasculature of zebrafish [19]. HoxC9 may also be involved in the

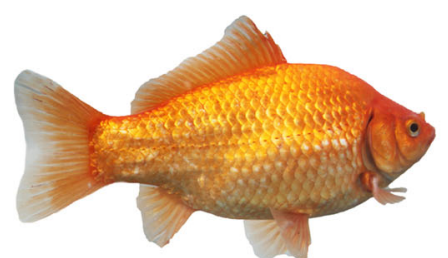

A $\operatorname{RCC}(2 \mathrm{n}=100$, 우 $)$

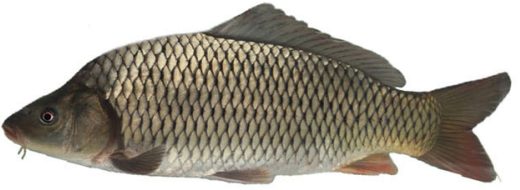

B CC $\left(2 n=100, \delta^{\Uparrow}\right)$
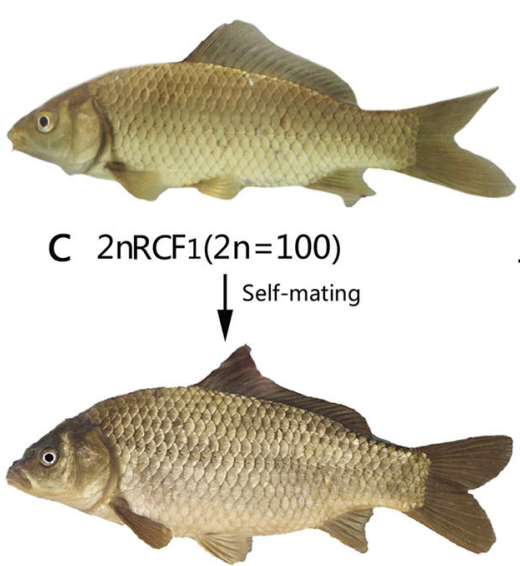

D $2 n R C F 2(2 n=100)$

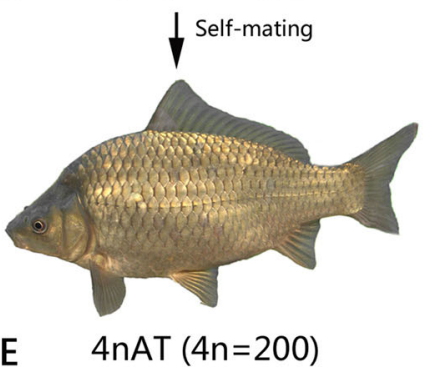

Fig. 1 Crossing procedure and appearances of $R C C, C C, 2 n R C F_{1}, 2 n R C F_{2}$ and $4 n A T$. a: $R C C ; \mathbf{b}: C C ; \mathbf{c}: 2 n R C F_{1} ; \mathbf{d}: 2 n R C F_{2} ; \mathbf{e}: 4 n A T$. Bar $=3 \mathrm{~cm}$ 
differentiation of bone marrow derived stem cells to endothelial cells because it was upregulated during stem cell differentiation [20]. Hox genes are clustered in the common ancestors of chordates, arthropods and nematodes and play an important role in embryogenesis by encoding transcription factors [21]. Therefore, Hox genes and Hox gene clusters may provide information about the process of evolution at the molecular level [22].

In this study, we compared the Hox genes of artificially derived 4nAT lineages with those of the original RCC and CC parents to obtain information on the genomic evolution of allopolyploid animals. Exploration of $4 \mathrm{nAT}$ and its related molecular genetic relationship with the parental lines can provide insight into the evolution of selected species. Specific genome replication provides an example for the evolution of fish.

\section{Results}

Sequence information for RCC, CC, and 4nAT

Using two pairs of degenerate primers, we obtained 90 sequences of PCR clones from RCC, 90 sequences from $\mathrm{CC}$, and 160 sequences from $4 \mathrm{nAT}$. To assign names to the Hox genes, all acquired sequences were screened for Hox gene fragments using BLAST searches against NCBI and were aligned using Clustal X (2.0) software for verification. According to BLAST searches and sequence alignment analysis, all but 17 sequences could be

Table 1 Summary of the PCR fragments from the 4nAT and its original parents

\begin{tabular}{|c|c|c|c|c|}
\hline \multirow[t]{2}{*}{ PG } & \multirow{2}{*}{$\begin{array}{l}\text { Gene } \\
\text { name }\end{array}$} & \multicolumn{3}{|c|}{ The total number of Hox gene fragments } \\
\hline & & RCC & CC & $4 n A T$ \\
\hline 1 & HoxB1b & 2 & 1 & 2 \\
\hline 2 & HoxA2b & & 1 & \\
\hline \multirow[t]{2}{*}{3} & НОXАЗа & 13 & 10 & 16 \\
\hline & НохВ3а & 7 & 9 & 8 \\
\hline 4 & HoxA4a & 1 & & \\
\hline \multirow[t]{2}{*}{5} & HOXA5a & 11 & 15 & 35 \\
\hline & HoxC5a & 3 & 1 & 4 \\
\hline 6 & HoxС6a & 1 & & \\
\hline 7 & HoxB7a & 4 & 2 & 5 \\
\hline 8 & HoxB8a & & 3 & 3 \\
\hline \multirow[t]{4}{*}{9} & HOXA9a & 1 & & 2 \\
\hline & HoxA9b & 3 & & \\
\hline & HoxB9a & 3 & 2 & 5 \\
\hline & $\mathrm{HoxC9a}$ & 5 & 5 & 13 \\
\hline \multirow[t]{4}{*}{10} & HoxA10b & 7 & 2 & 5 \\
\hline & HoxB10a & 1 & & 3 \\
\hline & HoxC10a & 13 & 14 & 22 \\
\hline & HoxD10a & & & 1 \\
\hline \multirow[t]{4}{*}{11} & HoxA11a & 3 & 2 & 3 \\
\hline & HoxA116 & & & 1 \\
\hline & HoxC11a & & & 1 \\
\hline & HoxD11a & & & 1 \\
\hline \multirow[t]{2}{*}{12} & HoxC12a & 2 & & \\
\hline & HoxD12a & & 1 & 1 \\
\hline \multirow[t]{5}{*}{13} & HoxA13a & 1 & 3 & 1 \\
\hline & HoxA13b & 1 & 1 & 3 \\
\hline & HoxB13a & 1 & 1 & \\
\hline & $\mathrm{HoxC13a}$ & 4 & 5 & 12 \\
\hline & HoxD13a & 1 & 5 & 5 \\
\hline Total & & 88 & 83 & 152 \\
\hline
\end{tabular}


assigned unambiguously to 29 distinct $H o x$ genes. A summary of the analyses and proposed gene identification was presented in Table 1 . The combined data of the PCR products yielded 22 distinct Hox gene fragments in RCC, 19 in CC, and 23 in 4nAT. Fifteen Hox gene fragments were found both in $4 \mathrm{nAT}$ and its original parents. Due to amplification bias during PCR amplification, we acquired more clones of HoxA3a, HoxA5a, and HoxC10a gene fragments than from other Hox genes. These Hox sequences were analyzed further. There were four isoforms in 4nAT (4nAT-I, 4nAT-II, 4nAT-III, and 4nAT-IV), two isoforms in RCC (RCC-I and RCC-II) and two isoforms in $\mathrm{CC}$ (CC-I and CC-II). Among the four isoforms of the HoxA5a gene, two were consistent with the HoxA5a gene in $\mathrm{CC}$ and the other two were consistent with the HoxA5a genes in RCC (Fig. 2a). The similarities between 4nAT-I and CC-I, 4nAT-II and RCC-I, 4nAT-III and CC-II, and 4nAT-IV and RCC-II were all $100 \%$. We detected two isoforms of HoxA3a and HoxC1Oa in the genome of CC and RCC. However, we observed only three isoforms of HoxA3a (Fig. 2b) and HoxC10a (Fig. 2c) in 4nAT. For HoxA3a, the identities between 4nAT-I and CC-I, 4nAT-I and RCC-I, 4nAT-II and CC-II, and 4nAT-II and RCC-II were all $100 \%$. For HoxC10a, the identities between 4nAT-I and CC-I, 4nAT-I and RCC-I, 4nAT-II and CC-II and 4nAT-III and RCC-II were all 100\%. Almost all orthologous sequences in both RCC and CC showed a higher percentage of similarity to each other than to their duplicated homeologous genes within species.

DNA fragments $(\sim 1800 \mathrm{bp})$ were amplified from RCC, $\mathrm{CC}$, and 4nAT using the primer pair HC9aF-HC9aR. The full-length $H o x C 9 a$ gene in RCC, CC, and 4nAT was 1837 bp (GenBank no: MN584925), 1834 bp (GenBank no: MN584926) and 1835 bp (GenBank no: MN584927), respectively. The homeodomain sequence of the $\mathrm{HoxC} 9 a$ gene was identical to the homeobox fragment $\mathrm{HoxC} 9 a$ isolated in the PCR survey. Interestingly, in $4 \mathrm{nAT}$, a new fragment of the HoxC9a gene was found, whose former part of nucleotide sequence was identical to that of the $\mathrm{CC}$ and the latter part was identical to that of RCC; the position of the exchange recombination occurred in the intron region (Fig. 3).

\section{Hybrid identification}

To determine if 4nAT was hybridized from RCC and CC, we examined the genomic composition of RCC, CC, and 4nAT using STRUCTURE. The genetic composition estimation was consistent with our sample collection. The two parental lines (RCC and CC) corresponded to the two clusters, and they were assigned exclusively to one of the two clusters (Fig. 4). All 4nAT individuals showed mixed ancestries (Fig. 4). This suggested that the 4nAT individuals genetically originated from RCC and CC.

\section{Phylogenetic relationships}

The identified Hox genes belonged to the paralogous groups $1,2,3,4,5,6,7,8,9,10,11,12$ and 13; however, we did not detect paralogous groups 4 and 6 in CC, paralogous groups 2 and 8 in RCC, and paralogous groups 2 , 4 and 6 in 4nAT. The phylogenetic analysis of the proteincoding nucleotide sequences assigned the obtained fragments to the expected orthologous genes among the three species (Fig. 4). Forty-two 4nAT, 29 RCC and 24 CC different subtypes of $H o x$ gene fragments were analyzed using the HKY + G + I model in MEGA 5.0 software to estimate the genetic divergence between the species. The phylogenetic tree of the genes was constructed by the ML method, according to genetic distance, and the confidence level (1000 bootstrap replicates) was tested with 1000 replicate samplings (Fig. 5). In this phylogenetic tree, essentially all of the 4nAT Hox genes were first aggregated with their related parents, RCC or CC, and then combined with other subtypes of this gene in $4 \mathrm{nAT}$ (Fig. 5). The phylogenetic tree showed that the genetic material of $4 \mathrm{nAT}$ originated from RCC and CC.

\section{Analysis of pseudogenes in $4 \mathrm{nAT}$ and the related parents}

A pseudogene was a sequence that existed in the genome of a specific population, and was typically characterized by being very similar to one or more paralogous genes, yet was nonfunctional. This loss of function was due to a failure in transcription or translation, or production of a protein that did not have the same function as the protein encoded by a normal paralog gene. Among the 152 Hox gene sequences in $4 \mathrm{nAT}$, we found that the HoxA1Ob and HoxC13a2 were pseudogenes. Two bases were missing in HoxA10b and the length of the HoxC13a gene subtype (HoxC13a2) with two inserted bases was $161 \mathrm{bp}$. Among the 88 Hox gene sequences of RCC, the HoxA11a2 was pseudogene. A base-deletion was found in the subtype (HoxA11a2) of HoxA11a gene and the length of the HoxA11a2 with base deletion was $158 \mathrm{bp}$. Using Jellyfish software (Version: V1.4_4383) to translate all the conserved sequence of these $H o x A 10 b$ genes into amino acids, the translation termination appeared in the coded region, in every case. The GC percentage (45.22\%) of the pseudogene $H o x A 10 b$ was significantly lower than AT percentage $(54.78 \%)$. Compared with the amino acid sequence of the HoxC13a gene (HoxC13a1) and HoxA11a gene (HoxA11a1), the amino acid sequence of HoxC13a2 with base insertion and HoxA11a2 with base deletion had changed greatly after these frameshift mutations, respectively (Fig. 6). The amino acid length of the pseudogenes (HoxA11a2: 51; HoxC13a2: 52) tended to be lower than that of their counterpart genes (HoxA11a1: 53; HoxC13a1:53). 


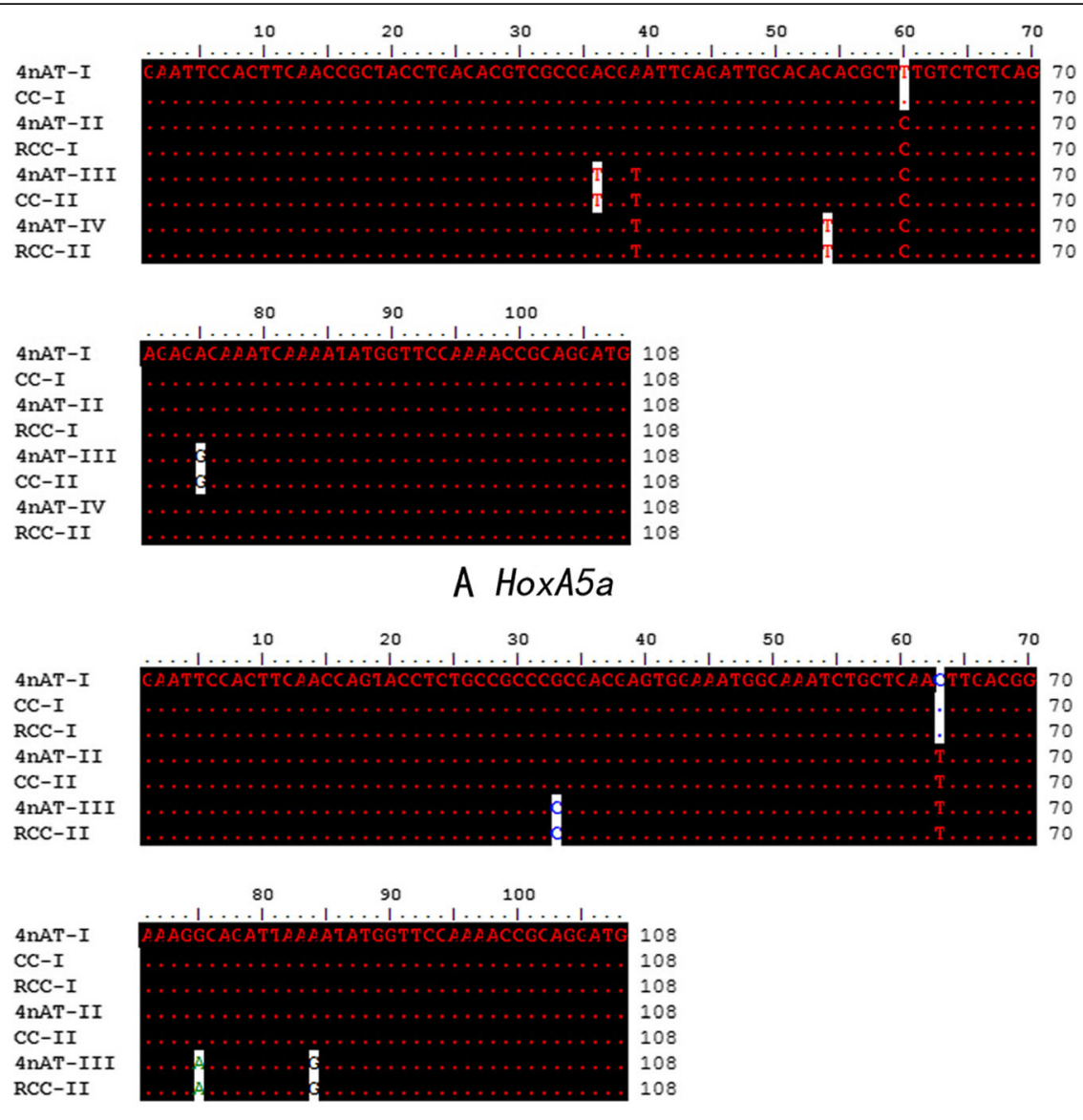

\section{B HoxA3a}
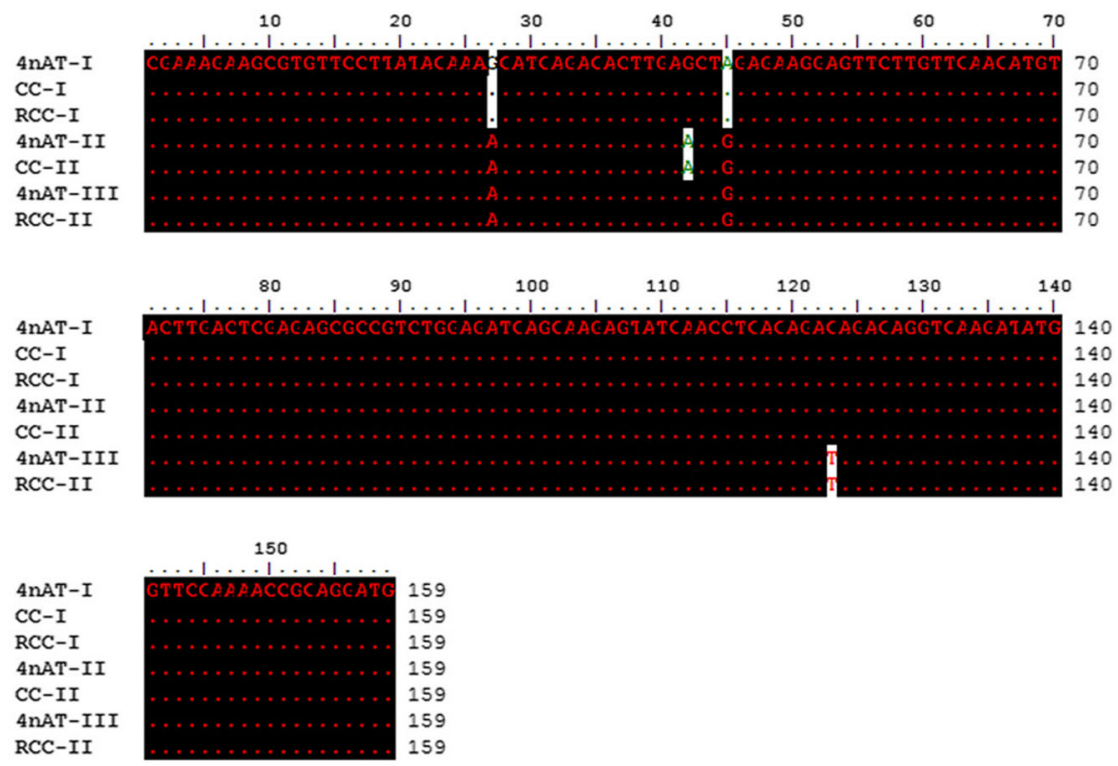

C HoxC10a

Fig. 2 (See legend on next page.) 
(See figure on previous page.)

Fig. 2 Comparison of the HoxA5a, HoxA3a, HoxC10a sequences from 4nAT, RCC and CC. CC-I and CC-II were two isoforms of HoxA5a from CC, RCC-I and RCC-II were two isoforms of HoxA5a from RCC, and 4nAT-I, 4nAT-II, 4nAT-III and 4nAT-IV were four isoforms of HoxA5a found in 4nAT. Dots indicated identical nucleotides at a given site (a). Comparisons of the HoxA3a (b) and HoxC10a (c) sequences from 4nAT, RCC and CC were found in B and C, respectively. CC-I and CC-II were two isoforms from CC, RCC-I and RCC-II were from RCC, and 4nAT-I, 4nAT-II and 4nAT-III were found in 4 AAT. Dots indicated identical nucleotides at a given site

\section{Molecular organization of the HoxC9a gene sequence}

We used the sequence from $4 \mathrm{nAT}$ to compare the obtained DNA sequences with the HoxC9a cDNA sequence of zebrafish (Danio rerio, BC165307) in GenBank (Fig. 7). Both ends of the sequence from 4nAT, RCC and CC resembled the HoxC9a cDNA sequence of zebrafish (NM_131528.3), while the intermediate sequence in $4 \mathrm{nAT}$ was an extra sequence, compared to the cDNA sequence in zebrafish (Fig. 7). The ends of the extra sequence were 'GT' and 'AG' using Jellyfish software alignment (539th position and 540th position: GT; 1616 th position and 1617 th position: AG). The intron junctions were consistent with the "GT-AG" rule in most species [23, 24]. The similarity of the $H o x C 9 a$ gene exon sequence between $4 \mathrm{nAT}$ and zebrafish, CC and zebrafish and RCC and zebrafish was 92.70, 92.80 and $91.90 \%$, respectively. The rule also indicated that the intermediate sequence in $4 \mathrm{nAT}, \mathrm{CC}$ and $\mathrm{RCC}$ were an intron, and the ends of the sequence were exon1 and exon2. We obtained the cDNA of the HoxC $9 a$ gene by excising the intron and ligating exon 1 and exon2. Then, the sequence was translated into putative amino acid sequences using Bioedit software (Version 7.0). The putative amino acid sequences of $H o x C 9 a$ in 4nAT, RCC and CC shared approximately 94.6, 93.8, and $94.6 \%$ similarity with that of zebrafish, respectively. All of our findings determined the identity of the PCR clones and the exon1-intron-exon2 structure of the $H o x C 9 a$ gene. The full-length $H o x C 9 a$ genes in $4 \mathrm{nAT}$, RCC and CC were obtained, and these sequences were compared and analyzed (Fig. 3). Sequence analysis indicated that the $\operatorname{HoxC} 9 a$ gene included exon1, intron and exon2. The intron junctions were consistent with the "GT-AG" rule. The two isoforms of the HoxC9a gene in $4 \mathrm{nAT}$ were from its original parents. Moreover, a recombinant isoform of the HoxC9a gene was found in 4nAT (Fig. 3).

\section{Discussion}

In this study, 29 Hox genes were screened in $4 \mathrm{nAT}$ and its parents (RCC and CC) using PCR. Among these, 23, 22 and 19 Hox genes were detected in $4 \mathrm{nAT}, \mathrm{RCC}$ and $\mathrm{CC}$, respectively. Compared with the Hox genes in zebrafish [25], all of the Hox genes detected here had homologous genes in zebrafish. The Hox genes in $4 \mathrm{nAT}, \mathrm{CC}$ and RCC were also found in goldfish with twin tails [26]. In tetraodon nigroviridis
[27], fugu rubripes [28], and medaka [29], the identified Hox genes did not have complete identity with the Hox genes in RCC, CC, and 4nAT. The HoxB10a and $H o x D 13 a$ genes were absent from the tetraodon nigroviridis, fugu rubripes, and medaka, but these genes were present in $4 \mathrm{nAT}$ and its related parents (RCC and CC). The retention and loss of genes may be associated with the evolutionary process [30]. These data allowed us to study the evolution of 4nAT after the doubling of the Hox gene cluster.

Many cloned fragments were obtained from Hox genes, such as HoxA3a, HoxA5a and HoxC10a, by PCR amplification. The length of these genes was $149 \mathrm{bp}$ in $4 \mathrm{nAT}$ and its parents. In $4 \mathrm{nAT}$, there were four subtypes of $H o x A 5 a$. Two had the same subtype as the HoxA5a gene of RCC, and two had the same subtype as the HoxA5a gene in CC. Three subtypes of the $\mathrm{HoxA} 3 a$ and $\mathrm{HoxC1Oa}$ genes were detected in $4 \mathrm{nAT}$, which also originated from RCC and CC. $H o x A 3 a, H o x A 4 a$ and HoxB4a from zebrafish were found in Oncorhynchus mykiss, and these genes in rainbow trout had two specific homologous zebrafish genes [31]. Two specific homologous zebrafish genes of the Hox gene in RCC and $\mathrm{CC}$ were found, and there were more subtypes in $4 \mathrm{nAT}$. These results suggested that genome duplication had occurred in other cyprinid fish. A comparison of the homologous parts of all subtypes of the Hox genes in the 4nAT, RCC and CC, showed that the homologous frame parts of the Hox genes in the 4nAT did not exhibit large-scale base mutations after doubling. The sequence of this segment was stable. The Hox genes in the $4 \mathrm{nAT}$ were more complex and abundant than those in RCC and CC.

After genome doubling, the new genome could face selection pressure, which could result in the evolution of new features. Genome duplication produced abundant genomic DNA, so the hybrid maintained the dosage balance or rapidly stabilized the duplicated genomes via retention/exclusion of redundancy. Lynch et al. [32] suggested three possible outcomes from the evolution of duplicate genes: non-functionalization, neofunctionalization and subfunctionalization. Duplicated genes were either retained without changes, mutated into other genes with new functions or degenerated into nonfunctional pseudogenes. We found that the $H o x A 10 b$ gene in 4 nAT exhibited two base deletions, while the HoxC13a gene had two base insertions. In the Hox gene sequence of RCC, a base deletion was also found in the HoxA11a gene sequence. However, 


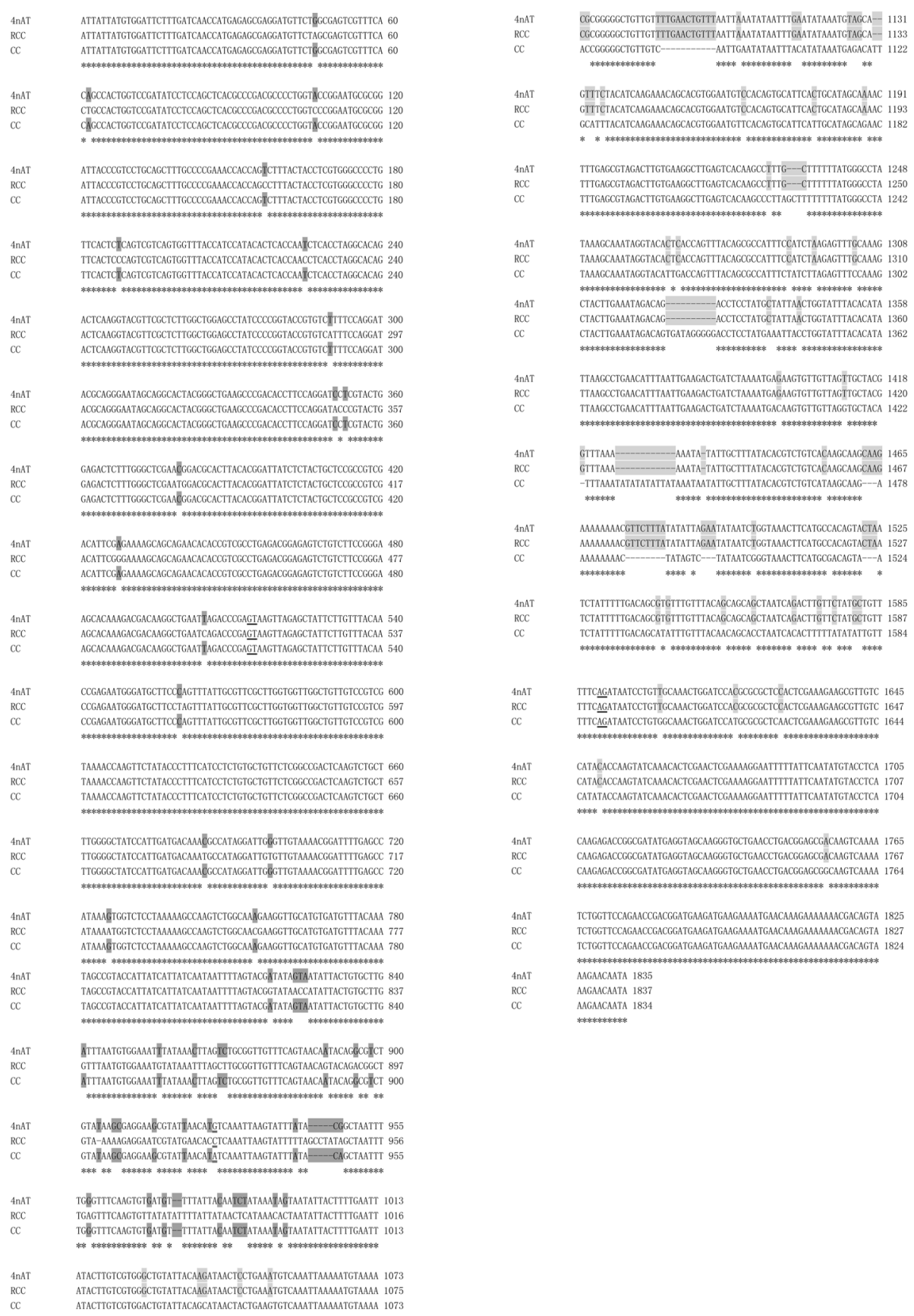

Fig. 3 Comparison of recombinant HoxC9a gene in 4nAT with HoxC9a gene in RCC and CC. Except for one nucleotide marked with the double underscore " $=$ ", which was inconsistent with both RCC and CC, the former part of nucleotide sequence of the recombinant HoxC9a gene that occurred in 4nAT was consistent with CC (position: 1-1026); the latter half was consistent with RCC (position: 1027-1825). The boundary bases of introns were underlined with "GT-AG"; "**" meant that the nucleotide was identical at this site

whether the Hox gene in $\mathrm{CC}$ also had this base variation remained unknown. The occurrence of these pseudogenes (HoxA10b, HoxA11a and HoxC13a) helped to reduce the pressure created by genome doubling. This pressure was consistent with the expectation that there were Hox clusters in the $4 \mathrm{nAT}$ genome that had lost functional Hox genes due to the reduction of redundancy of the Hox genes due to the polyploidization event. In the hybridization process, $4 \mathrm{nAT}$ required genetic recombination, mutation, and pseudogenization to reduce the amount of incompatible genetic material and improve fertility [13]. Thus, 


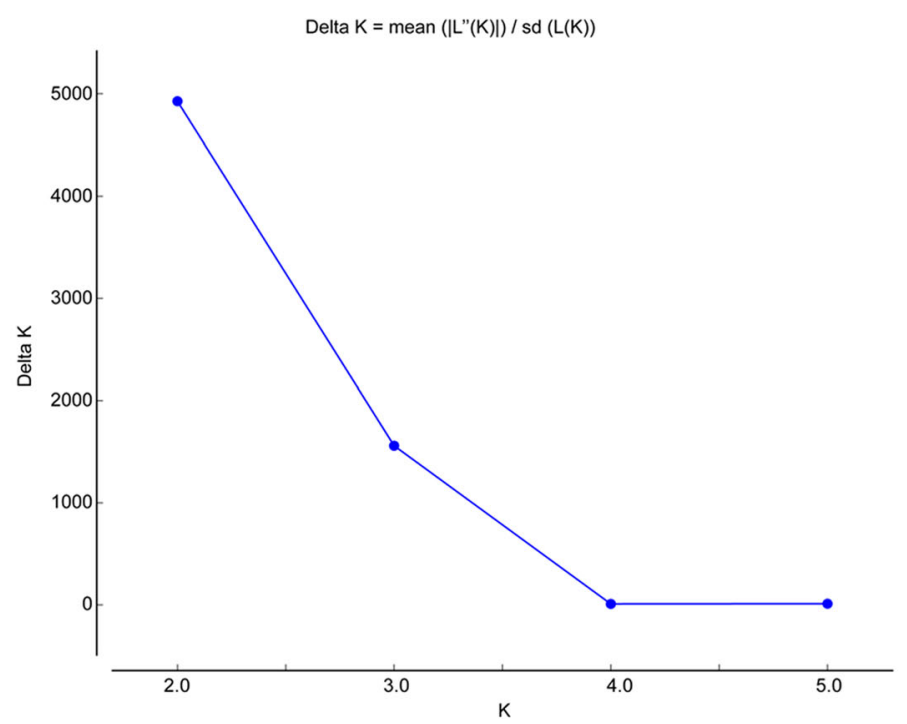

(A)

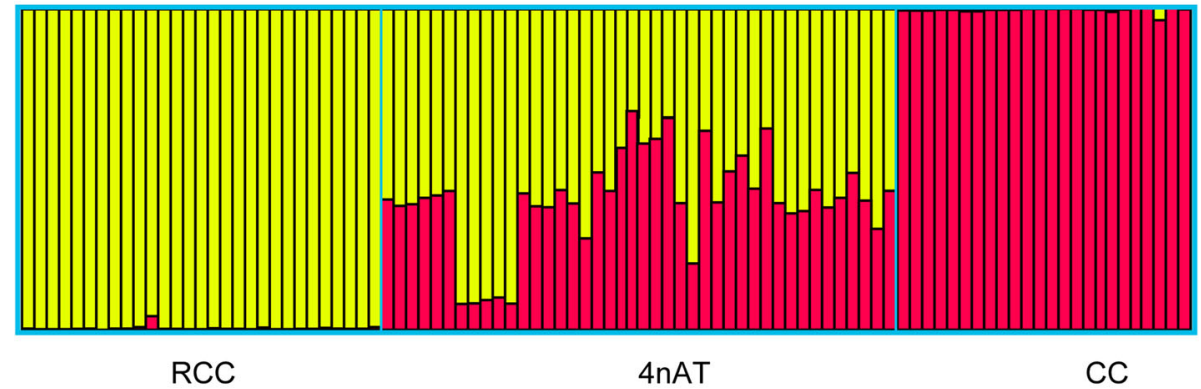

(B)

Fig. 4 Genetic composition of RCC, CC and 4nAT. STRUCTURE displayed for the optimal number of clusters (K=2) (a). RCC cluster was yellow and CC cluster was Red (b)

we established an allotetraploid fish lineages [7]. The results indicated that the genome after doubling could reduce redundant genes by formation of pseudogenes, as indicated by the Hox gene in $4 \mathrm{nAT}$. Characterization of the Hox gene clusters in allotetraploid hybrids increased understanding of the evolutionary process which occurred after Hox gene doubling.

We cloned the full-length sequence of the $\mathrm{Hox} C 9 a$ gene, and its structure was divided into three parts: exon1, intron and exon2. This result was consistent with the Hox structure described in previous reports [33, 34], in which the bases of the introns conformed to the GT-AG rule. Analysis of the HoxC9a genes in RCC, CC and 4nAT, showed that genetic recombination occurred in $4 \mathrm{nAT}$, and the intron region occurred in the recombination region. The former part was consistent with $\mathrm{CC}$, and the latter part was consistent with RCC. This recombinant gene indicated that 4nAT underwent meiosis, alien chromosome synapsis and exchange recombination. The exchange recombination provided a genetic basis for the variation and diversity of the $4 \mathrm{nAT}$ and provided raw materials which might facilitate species adaptation and evolution.

In summary, we investigated the gene organization and structures of $H o x$ in $4 \mathrm{nAT}$ and its parents. There was significant variation in Hox genes, which enabled rapid genomic evolution in $4 \mathrm{nAT}$ after hybridization and polyploidization. In fish, hybridization and polyploidization could help drive speciation by changing genome structures and generating new genes.

\section{Conclusions}

We found four copies of Hox genes in the 4nAT, two copies in RCC and two copies in CC. Obvious variation and pseudogenization were found in some Hox genes of the $4 \mathrm{nAT}$. These results revealed the effects of polyploidization on the organization and evolution of Hox gene clusters in 


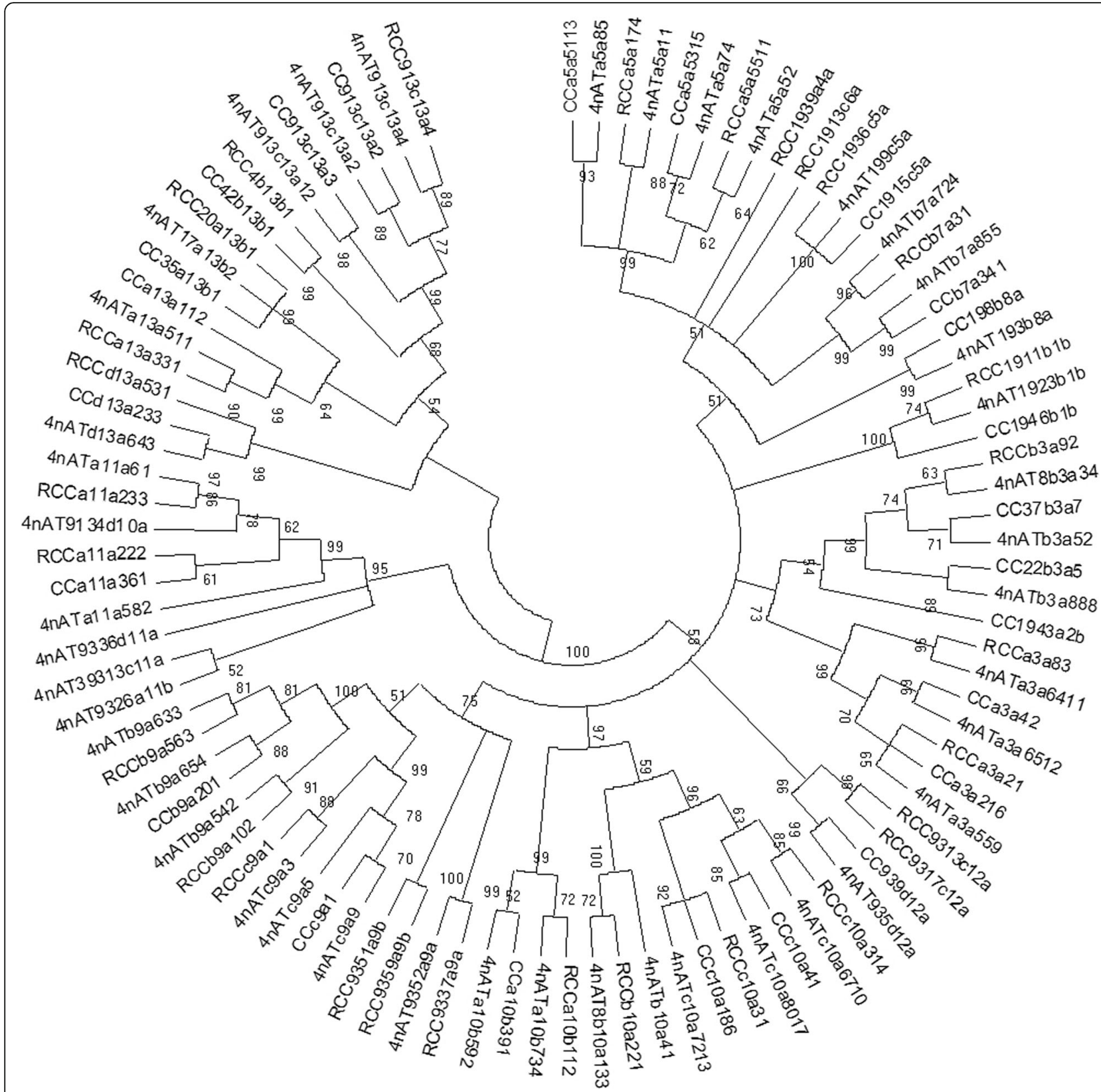

Fig. 5 Amino acid-based Maximum Likelihood tree represented the phylogenetic relationships of the putative Hox genes obtained from 4nAT, RCC and CC. The number at each node represented the percentage bootstrap value of 1000 replicates. The number on the horizontal line represented the self-expanding value

fish, and helped to clarify aspects of vertebrate genome evolution.

\section{Methods}

\section{Samples and ethics statement}

RCC, CC and 4nAT were obtained from State Key Laboratory of Developmental Biology of Freshwater Fish, Hunan Normal University, Changsha, Hunan, China. The procedures were conducted in accordance with approved guidelines. Fish were housed in open pools $(0.067 \mathrm{ha})$ with a suitable $\mathrm{pH}(7.0-8.5)$, water temperature $\left(22-24^{\circ} \mathrm{C}\right)$, and dissolved oxygen content $(5.0-8.0 \mathrm{mg} / \mathrm{L})$ and with adequate food. The fish used for blood samples were anesthetized with $100 \mathrm{mg} / \mathrm{L} \mathrm{MS}-222$ (Sigma-Aldrich, St. Louis, MO, United States).

\section{DNA extraction}

One-year-old 4nAT, one-year-old RCC, and one-year-old CC, were randomly selected. Peripheral blood was collected from the caudal vein of each fish (for total genomic 


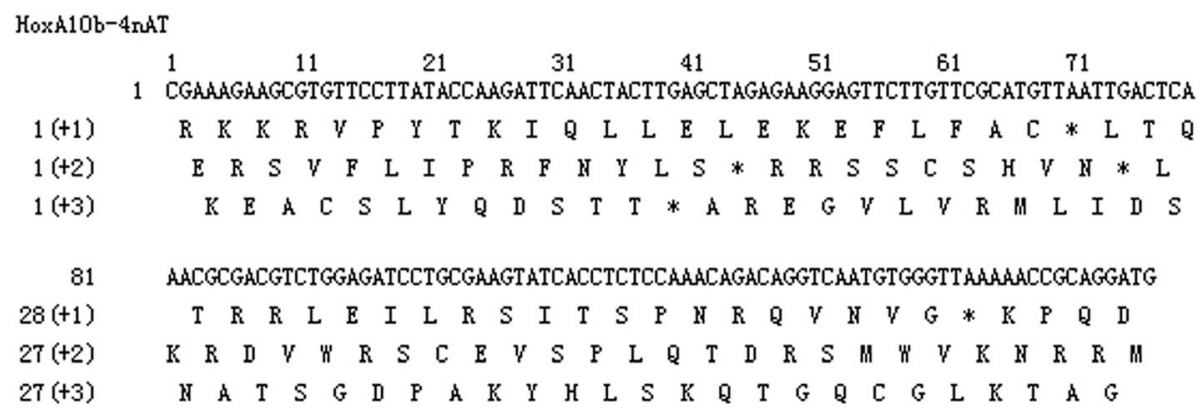

A

Hox.11a1 RKKSWPYTKFQIRELEREFFFSWIMEKRVQL SRMLNL TDRQWKIWFQNRRM-

HoxA11a2 RKKSURIQNFKSGSSRGNFSSACTL TKRNEFSSQGCL---TSPIAKKCGSKTAG

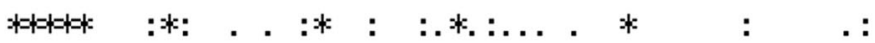

B

HoxC13a1 RKKRTPTKIQLKELEKEYASSKFTKDKRRRISATTIL SERQUTIUFQNRRM-

HoxC13a2 RKRRTPTPRYNRWHKSMQQASLLPKTRDD--ASLRQPTSQNAFLLCGSKTAG

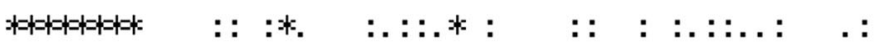

\section{C}

Fig. 6 The pseudogenes HoxA10b and HoxC13a2 in 4nAT and the pseudogene HoxA11a2 in RCC. a: listed all the possible amino acid sequences of HoxA10b gene in 4nAT which had base deletions. "*" meant that this site was a terminator when a nucleotide was translated into an amino acid. $\mathbf{b}$ and $\mathbf{c}$ reflected transcoding mutations in HoxA11a and HoxC13a genes. The amino acid sequences of HoxA11a and HoxC13a were expressed as HoxA11a1 and HoxC13a1, respectively. HoxA11a2 meant that the amino acid sequence of HoxA11a gene with the deletion of base, and HoxC13a2 was on behalf of the amino acid sequence of HoxC13a gene with the insertion of base. "**" represented the same amino acid at this site; ":" meant that this site was a conservative mutation; "." indicated that the position was a semi-conservative mutation; The blank space represented a large variation in the position

DNA extraction). Total genomic DNA was isolated from blood cells following the manufacturer's instructions (Sangon, Shanghai, China). The concentration and quality of DNA was assessed using agarose gel electrophoresis.

\section{PCR amplification, cloning, and sequencing}

PCR amplification of $108 \mathrm{bp}$ of the highly conserved homeobox PG1-9 was performed using a degenerate homeobox primer pair: forward primer [5'-GAA TTC CAC TTC AAC (C/A)(G/A)(C/G) TAC CT-3'] and reverse primer [5'-CAT CCT GCG GTT TTG GAA CCA NAT-3']. PCR amplification of $159 \mathrm{bp}$ of the highly conserved homeobox PG9-13 was performed using a degenerate homeobox primer pair: forward primer [5' CGA AAG (C/A)G(N/C) GT(N/C) CC(N/C) TA(T/C) AC-3'] and reverse primer [5'-CAT CCT GCG GTT TTG GAA CCA NAT-3'] as described by Amores et al. (2004) [35]. We used Primer Premier 5.0 to design a pair of degenerate primers [HC9aF, 5'-ATT ATT ATG TGG $\mathrm{A}(\mathrm{C} / \mathrm{T}) \mathrm{T} \mathrm{C}(\mathrm{C} / \mathrm{T})$ T TGAT-3'; HC9aR, 5'-TA(C/T) TGT TC(C/T) TT(A/G) CTG TCG TT(C/T) T-3'] based on nucleotide and amino acid sequences of HoxC9a in zebrafish (Danio rerio), pufferfish species (Takifugu rubripes and Tetraodon nigroviridis) and 


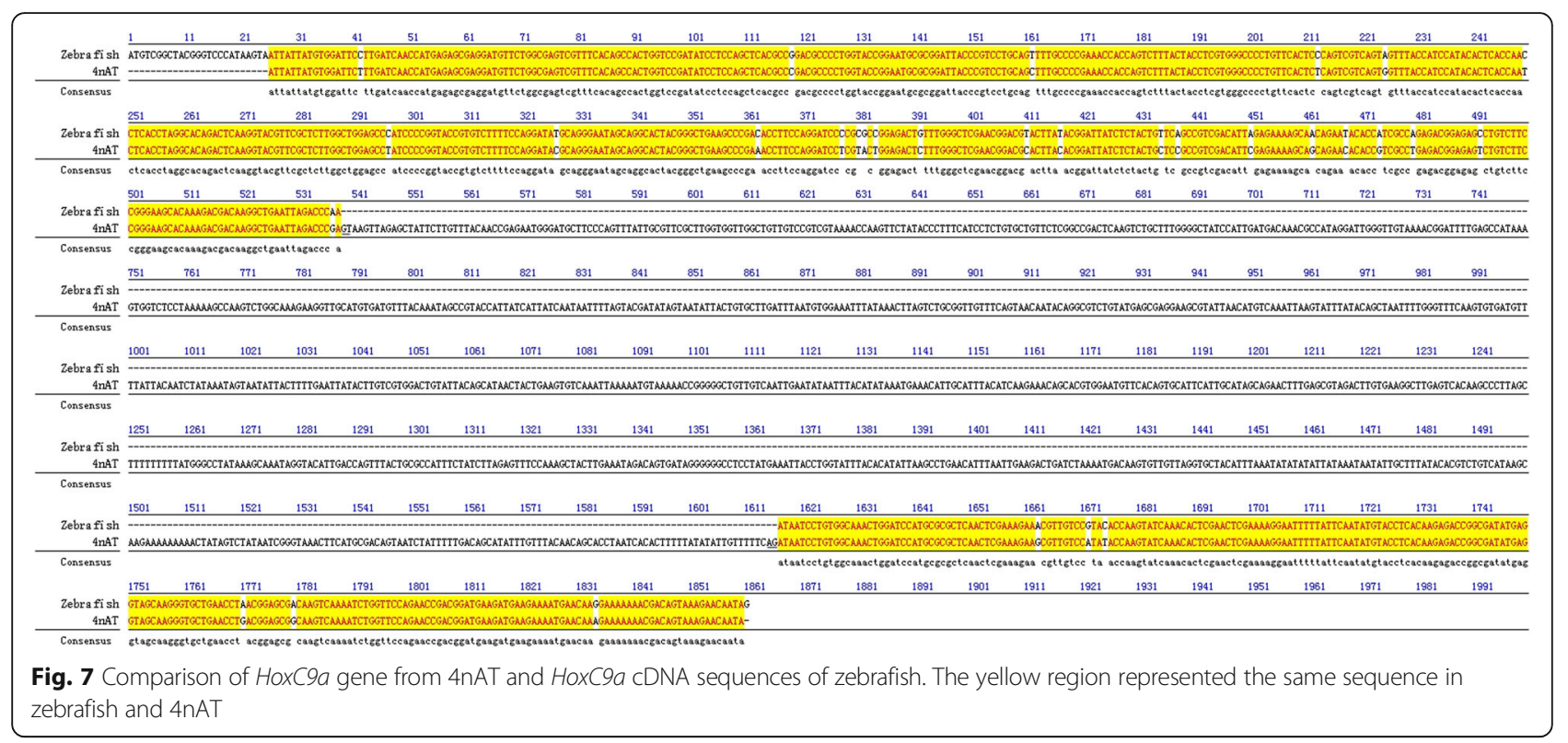

medaka (Oryzias latipes). Amplification was carried out in a $20 \mu \mathrm{l}$ reaction volume containing $2.0 \mu \mathrm{l} 10 \times \mathrm{PCR}$ buffer, $1.6 \mu \mathrm{l} 25 \mathrm{mM} \mathrm{MgCl} 2,1.6 \mu \mathrm{l} 2.5 \mathrm{mM}$ dNTPs, $0.6 \mu \mathrm{l}$ $10 \mu \mathrm{M}$ forward and reverse primers, $0.4 \mu \mathrm{l} 2.5 \mathrm{U} / \mu \mathrm{l}$ Taq DNA polymerase (Tiangen, Beijing, China), and approximately $100 \mathrm{ng}$ genomic DNA. PCR was carried out under the following standard cycle: one denaturation step at $94{ }^{\circ} \mathrm{C}$ for $5 \mathrm{~min}, 30$ cycles of $94{ }^{\circ} \mathrm{C}$ for $30 \mathrm{~s}, 55^{\circ} \mathrm{C}$ for $30 \mathrm{~s}$ and $72^{\circ} \mathrm{C}$ for $1 \mathrm{~min}$, followed by a final extension step at $72{ }^{\circ} \mathrm{C}$ for $5 \mathrm{~min}$. All amplified fragments were purified by a gel extraction kit and ligated into a $p M D 18$-T vector (Takara, Dalian, China) following the manufacturer's protocol. The plasmids were transformed into E. coli $\mathrm{DH} 5 \alpha$. The clones were identified by PCR amplification and sequenced by an automated DNA sequencer (ABI PRISM 3730).

\section{Analyses of PCR fragments}

All raw sequence data were verified manually from electropherograms using the Chromas version 1.62 programs (Technelysium, Australia). The $108 \mathrm{bp}$ and 149 bp sequences of the PG1-9 and PG9-13 homeoboxes, respectively, were screened for Hox genes using BLAST searches against NCBI. The $\sim 1500 \mathrm{bp}$ long sequences of $H o x C 9 a$ were screened for Hox genes using BLASTX and BLASTN to determine their identity. The alignment of each PCR fragment to one of the paralog groups (Hox1-Hox13) was initially determined based on nucleotide and amino acid sequence similarities to published Hox sequences using BLAST (http://www.ncbi.nlm.nih.gov/BLAST/).

\section{Sequence comparison and analysis}

Sequence homology and variation among the fragments amplified from RCC, CC and 4nAT were analyzed in Bioedit (Version 7.0). Partial DNA sequences for each gene were verified via a BLASTX search. To increase the probability of detecting duplicated paralogs and avoiding PCR errors, we sequenced 30 clones of each gene for RCC, CC and 4nAT. BLASTX and BLASTN searches of the GenBank database were initially made to determine the identity of the PCR clones. Then, the DNA sequences were compared with the HoxC9a cDNA sequence of zebrafish ( $D a$ nio rerio, BC165307) in GenBank using the Jellyfish software to identify the exon1-intron-exon2 structure of the $\mathrm{HoxC} 9 a$ gene. The intron junctions were consistent with the "GT-AG" rule in most species and the rule was used to reconfirm the position of the intron of the $\mathrm{HoxC} 9 a$ gene. We obtained the cDNA of the $\mathrm{Hox} C 9 a$ gene by excising the intron and ligating exon1 and exon2, and then the sequence was translated into putative amino acid sequences using Bioedit software (Version 7.0). The work above was performed to determine the identity of the PCR clones and the exon1-intron-exon2 structure of the HoxC9a gene.

\section{Genetic composition analysis}

To determine if $4 \mathrm{nAT}$ individuals genetically originated from RCC and CC, we inferred genomic composition with Hox gene haplotypes using STRUCTURE [36]. We ran STRUCTURE for K-values varying from 1 to 6, with 20 replicates at each $\mathrm{K}$. Each replicate run had a total of 100,000 iterations, with the first 50,000 discarded as burn-in. The optimal K-value was 2 (Fig. 4a) in the analysis with STRUCTURE HARVESTER [37]. We 
combined the 20 runs at $\mathrm{K}=2$ using CLUMPP [38] and conducted a graphical display by DISTRUCT [39].

\section{Phylogenetic analysis}

The Hox gene sequences were aligned using ClustalX software [40] and a Maximum Likelihood (ML) phylogenetic tree was constructed using MEGA 5.0 software [41]. We assigned PCR fragments based on the identity of the subtree in which they were located. Phylogenetic analysis was performed by ML methods and the bestfitting nucleotide substation model with the lowest BIC score was determined by using MEGA5 [42]. Conserved regions were determined using the Gblocks program. ML analyses were performed using the GTR + G model, and the robustness of the tree topology was assessed with 1000 bootstrap replicates [43].

\section{Abbreviations}

$2 n R C F_{1}$ : The first-generation diploid hybrids of RCC $(+) \times C C(\delta) ; 2 n R C F_{2}$ : The self-mating of $2 \mathrm{nRCF}_{1} ; 4 \mathrm{nAT}$ : Allotetraploid hybrids; CC: Common carp; RCC: Red crucian carp

\section{Acknowledgements}

We would like to sincerely thank the researchers who helped to complete this manuscript, including professor Zongzhao Zhai, associate professor Yi Zhou, Dr Shi Wang.

\section{Authors' contributions}

RR.Z, YD. W, and SJ. L designed the study, carried out the analyses, performed the technical discussions, prepared and draft the manuscript. L. Z, YX. L and HF. T participated in data collection and discussions. JJ. Y and MH. Z were involved in the statistical analysis. All the authors read and approved the final manuscript.

\section{Funding}

This work was supported by the National Natural Science Foundation of China (Grant No. 31430088, 31730098, 31702328), the Key Research and Development Project of Hunan Province (Grant No. 2016NK2130), the earmarked fund for China Agriculture Research System (Grant No.CARS-45), Hunan Provincial Natural Science and Technology Major Project (Grant No.2017NK1031), the China Postdoctoral Science Foundation (Grant No. 2019M662788), the Cooperative Innovation Center of Engineering and New Products for Developmental Biology of Hunan Province (Grant No.20134486). Funds for this project provided funding for reagents, consumables, and laboratory apparatus for this study. The funding bodies played no role in the design of the study and collection, analysis, and interpretation of data and in writing the manuscript.

\section{Availability of data and materials}

The datasets supporting the conclusions of this article were available in the GenBank repository with access No. MN584925-MN584927.

\section{Ethics approval and consent to participate}

All experiments were approved by the Animal Care Committee of Hunan Normal University and followed the guidelines statement of the Administration of Affairs Concerning Animal Experimentation of China. All fish used as the samples were anesthetized with $100 \mathrm{mg} / \mathrm{L} \mathrm{MS-222} \mathrm{(Sigma-Al-}$ drich, St. Louis, MO, United States) before dissection and all efforts were made to minimize suffering.

\section{Consent for publication}

Not applicable.

\section{Competing interests}

The authors declared that they had no competing interests.

\section{Author details}

'State Key Laboratory of Developmental Biology of Freshwater Fish, Hunan Normal University, Changsha 410081, Hunan, People's Republic of China. ${ }^{2}$ College of Life Sciences, Hunan Normal University, Changsha 410081, Hunan, People's Republic of China. ${ }^{3}$ Fisheries Research Institute of Hunan Province, Changsha 410153, People's Republic of China.

Received: 28 October 2019 Accepted: 4 February 2020

Published online: 04 March 2020

\section{References}

1. Barker MS, Husband BC, Pires JC. Spreading Winge and flying high: the evolutionary importance of polyploidy after a century of study. Am J Bot. 2016;103(7):1139.

2. dPY V, Mizrachi E, Marchal K. The evolutionary significance of polyploidy. Nat Rev Gene. 2017:18(7):411-24.

3. Otto SP. The evolutionary consequences of polyploidy. Cell. 2007;131(3): 452-62.

4. McClintock B: The significance of responses of the genome to challenge. 1983.

5. Cox MP, Dong T, Shen G, Dalvi Y, Scott DB, Ganley AR. An interspecific fungal hybrid reveals cross-kingdom rules for allopolyploid gene expression patterns. PLoS Genet. 2014;10(3):e1004180.

6. Gerstein AC, Chun H-JE, Grant A, Otto SP. Genomic convergence toward diploidy in Saccharomyces cerevisiae. PLoS Genet. 2006;2(9):e145.

7. Liu S, Luo J, Chai J, Ren L, Zhou Y, Huang F, Liu X, Chen Y, Zhang C, Tao M. Genomic incompatibilities in the diploid and tetraploid offspring of the goldfishx common carp cross. Proc Natl Acad Sci. 2016;113(5):1327-32.

8. Moshe F, Levy AA. Genome evolution due to allopolyploidization in wheat. Genetics. 2012;192(3):763-74.

9. Abbott R, Albach D, Ansell S, Arntzen JW, Baird SJ, Bierne N, Boughman J, Brelsford A, Buerkle CA, Buggs R. Hybridization and speciation. J Evol Biol. 2013;26(2):229-46

10. Liu S, Liu Y, Zhou G, Zhang X, Luo C, Feng H, He X, Zhu G, Yang H. The formation of tetraploid stocks of red crucian carpX common carp hybrids as an effect of interspecific hybridization. Aquaculture. 2001:192(2-4):171-86.

11. Liu S. Distant hybridization leads to different ploidy fishes. Sci China Life Sci. 2010:53(4):416-25

12. Song C, Wang J, Liu S, Qin Q, Xiao J, Duan W, Luo K, Liu J, Liu Y. Biological characteristics of an improved triploid crucian carp. Sci China. 2009:52(8):733-8.

13. Wang J, Ye L, Liu Q, Peng L, Liu W, Yi X, Wang Y, Xiao J, Xu K, Hu F, Ren L, Tao M, Zhang C, Liu Y, Hong Y, Liu S. Rapid genomic DNA changes in allotetraploid fish hybrids. Heredity. 2015;114(6):601-9.

14. Santini S, Bernardi G. Organization and base composition of tilapia Hox genes: implications for the evolution of Hox clusters in fish Gene. 2005;346(346):51-61.

15. Koh EGL, Lam K, Christoffels A, Erdmann MV, Brenner S, Venkatesh B. Hox gene clusters in the Indonesian coelacanth, Latimeria menadoensis. Proc Natl Acad Sci U S A. 2003:100(3):1084-8.

16. Mallo $\mathrm{M}$, Alonso CR. The regulation of Hox gene expression during animal development. Development. 2013;140(19):3951-63.

17. Lemons D, McGinnis W. Genomic evolution of Hox gene clusters. Science. 2006:313(5795):1918-22.

18. Pruett ND, Visconti RP, Jacobs DF, Scholz D, McQuinn T, Sundberg JP, Awgulewitsch A. Evidence for Hox-specified positional identities in adult vasculature. BMC Dev Biol. 2008;8(1):93.

19. Thisse B, Thisse C: Fast release clones: a high throughput expression analysis. ZFIN direct data submission 2004

20. Chung N, Jee BK, Chae SW, Jeon Y-W, Lee KH, Rha HK. HOX gene analysis of endothelial cell differentiation in human bone marrowderived mesenchymal stem cells. Mol Biol Rep. 2009;36(2):227-35.

21. Mcginnis W, Krumlauf R. Homeobox genes and axial patterning. Cell. 1992; 68(2):283-302

22. Holland PWH, Garcia-Fernàndez J. HoxGenes and chordate evolution. Dev Biol. 1996;173(2):382-95.

23. Ohno K, Ji T. Masuda a: rules and tools to predict the splicing effects of exonic and intronic mutations. Wiley Interdiscip Rev RNA. 2018;9(1): e1451.

24. Harada N, Yamada K, Saito K, Kibe N, Dohmae S, Takagi Y. Structural characterization of the human estrogen synthetase (aromatase) gene. Biochem Biophys Res Commun. 1990;166(1):365-72. 
25. Postlethwait JH, Yan Y-L, Gates MA, Horne S, Amores A, Brownlie A, Donovan A, Egan ES, Force A, Gong Z, et al. Vertebrate genome evolution and the zebrafish gene map. Nat Genet. 1998;18(4):345-9.

26. Luo J, Stadler PF, He S, Meyer A, Luo J, Stadler PF, He S, Meyer A. PCR survey of Hox genes in the goldfish Carassius auratus auratus. J Exp Zool B Mol Dev Evol. 2010;308B(3):250-8.

27. Jaillon O, Aury J-M, Brunet F, Petit J-L, Stange-Thomann N, Mauceli E, Bouneau L, Fischer C, Ozouf-Costaz C, Bernot A. Genome duplication in the teleost fish Tetraodon nigroviridis reveals the early vertebrate protokaryotype. Nature. 2004;431(7011):946.

28. Aparicio S. Whole-genome shotgun assembly and analysis of the genome of Fugu rubripes. Science. 2002;297(5585):1301-10.

29. Naruse K, Fukamachi S, Mitani H, Kondo M, Matsuoka T, Shu K, Hanamura N, Morita Y, Hasegawa K, Nishigaki R. A detailed linkage map of Medaka, Oryzias latipes: comparative genomics and genome evolution. Genetics. 2000;154(4):1773-84

30. Hoegg S, Meyer A. Hox clusters as models for vertebrate genome evolution Trends Genet. 2005;21(8):421-4.

31. Moghadam HK, Ferguson MM, Danzmann RG. Evidence for Hox gene duplication in rainbow trout (Oncorhynchus mykiss): a Tetraploid model species. J Mol Evol. 2005;61(6):804-18.

32. Lynch M, Conery JS. The evolutionary fate and consequences of duplicate genes. Science. 2000;290(5494):1151-5.

33. Zou S-M, Jiang X-Y, He Z-Z, Yuan J, Yuan X-N, Li S-F. Hox gene clusters in blunt snout bream, Megalobrama amblycephala and comparison with those of zebrafish, fugu and medaka genomes. Gene. 2007:400(1-2):60-70.

34. Xue L, Qian K, Qian H, Li L, Yang Q, Li M. Molecular cloning and characterization of the Myostatin gene in Croceine croaker, Pseudosciaena crocea. Mol Biol Rep. 2006;33(2):129-35.

35. Amores A, Suzuki T, Yan YL, Pomeroy J, Singer A, Amemiya C, Postlethwait $\mathrm{JH}$. Developmental roles of Pufferfish Hox clusters and genome evolution in ray-fin fish. Genome Res. 2004;14(1):1-10.

36. Pritchard JK, Stephens M, Donnelly P. Inference of population structure using multilocus genotype data. Genetics. 2000;155(2):945-59.

37. Earl DA. STRUCTURE HARVESTER: a website and program for visualizing STRUCTURE output and implementing the Evanno method. Conserv Genet Resour. 2012;4(2):359-61.

38. Jakobsson M, Rosenberg NA. CLUMPP: a cluster matching and permutation program for dealing with label switching and multimodality in analysis of population structure. Bioinformatics. 2007;23(14):1801-6.

39. Rosenberg NA. DISTRUCT: a program for the graphical display of population structure. Mol Ecol Notes. 2004;4(1):137-8.

40. Thompson JD, Gibson TJ, Higgins DG. Multiple Sequence Alignment Using ClustalW and ClustalX. Curr Protoc Bioinform. 2002:Chapter 2(Unit 2):Unit 2.3.

41. Cummings MP: MEGA (molecular evolutionary genetics analysis); 2004

42. Gao F, Lin W, Shen J, Liao F. Genetic diversity and molecular evolution of arabis mosaic virus based on the CP gene sequence. Arch Virol. 2016;161(4): 1047-51.

43. Yang Z, Rannala B. Molecular phylogenetics: principles and practice. Nat Rev Genet. 2012;13(5):303.

\section{Publisher's Note}

Springer Nature remains neutral with regard to jurisdictional claims in published maps and institutional affiliations.

Ready to submit your research? Choose BMC and benefit from:

- fast, convenient online submission

- thorough peer review by experienced researchers in your field

- rapid publication on acceptance

- support for research data, including large and complex data types

- gold Open Access which fosters wider collaboration and increased citations

- maximum visibility for your research: over $100 \mathrm{M}$ website views per year

At BMC, research is always in progress.

Learn more biomedcentral.com/submissions 